\title{
Smart Home Electricity Management System Using Cloud Computing (SHEMS)
}

\author{
Marvin R. G. Garcia, Hannah R. B. Chan, Benilda E. V. Comendador, Grant B. Cornell, Christopher \\ D. Celestial, and Arc E. P. Mercolesia
}

\begin{abstract}
The paper promotes Smart Home Electricity Management System using Cloud Computing (SHEMS). Through the Internet it can collect on-line data power consumption, and can manipulate the power supply of the connected electrical appliances. In addition, it can generate daily, monthly and yearly reports on cost and kilo-watt per hour usage of each appliances/loads connected to the system. Thus, it enables the consumer or establishment to keep track the real-time power consumption which allows users to save electrical energy.
\end{abstract}

Index Terms-Cloud computing, electric energy management, energy saving, remote supervisory control, smart home.

\section{INTRODUCTION}

Nowadays, web technology can deliver signals which can control electrical devices connected to the Internet which enable the users to control them anywhere. This new generation technology is the integration of Cloud Computing and Smart Home. Cloud Computing is the delivery of computing as a service rather than a product. It can share resources, software, and information to computers and other devices as a utility (like the electricity grid) over a network (typically the Internet). Most of large companies are using this technology primarily to cut costs [1]. This technology provides resources and infrastructure as a source rather than capital expenditure that would mitigate the institution's outlay on resources [2]. In addition, IBM said "Cloud computing is expected to reduce by 40 percent the costs in hardware and software maintenance, which make up around 30 percent of a typical company's operational expenses" [3].

On the other hand, Smart Home incorporates communications network that connects the key electrical appliances and services, and allows them to be remotely controlled, monitored or accessed [4].

Currently, there are limited researches focusing on the integration of Cloud Computing and Smart Home. For instance, in the study by Al-Ali and Al-Rousan, they designed a "Java-based automation System" which utilized

Manuscript received October 10, 2012; revised December 22, 2012 This work was supported by the Polytechnic University of the Philippines.

M. G. Garcia, H. B. Chan, B. E. V. Comendador, C. D. Celestial, and A. E. P. Mercolesia are with the Polytechnic University of the Philippines (email: marvin_garcia_25@yahoo.com, hannahchan_24@yahoo.com, bennycomendador@yahoo.com,_celestialchristopher@gmail.com, aezekiel.mercolesia@yahoo.com).

G. B. Cornell is with the Polytechnic University of the Philippines and Eulogio Amang Rodriguez Institute of Technology, Philippines.
Cloud Computing and Smart Home concepts. It controls and monitors the home appliances via the World Wide Web but it lacks the consumption computation of the appliances connected [5]. In another project by Liang, $\mathrm{Fu}$, and $\mathrm{Wu}$ they explored the same concept which can monitor and control appliances through embedded microprocessors and be displayed on terminals [6]. However, efficient and full utilization of Smart Home and Cloud Computing are still not fully maximized yet.

In the work by Adao, Antunes, and Grilo they developed a web-based control and notification for home automation alarm systems. It proves that it is possible to obtain low cost alarm systems and control monitor solution for home owners. Conversely, the said project focuses on the implementation of smart home with alarm system but it cannot be accessed remotely [7]. Consequently, Khiyal, Khan, and Shehzadi conducted similar study which is Short Message Service (SMS) based but they just simulated the control of home appliances remotely and provided security when the user is away from the place. Also, it has no features on monitoring the energy consumption [8]. Thus, in this study the authors attempted to focus on the full integration of Cloud Computing and Smart Home concepts.

\section{THE DEVEloped SYSTEM}

The SHEMS consists of a Controller (Web server), website, hardware interface and the software application for monitoring the electrical switch control. The developed system is integrated with an electricity flow switch which control the appliance switching on and switching off remotely. The real time monitoring of the overall electricity consumption in terms of per Kilowatt hour (KWH) and its cost (equivalent price of KWH consumed) are presented in graphical reports. This feature may encourage households to be watchful on energy consumption.

The said system can shut out access from anyone who will attempt and explore it with no recognized code. This mechanism protects SHEMS from those who will try to gain unauthorized access that will violate its security, interfere its availability, data integrity and its confidentiality. SHEMS integrates Virtual Private Network (VPN). It authenticates the remote access and utilizes encryption techniques to ensure its security[9].

\section{A. System Architecture}

Fig. 1 shows the System Architecture. The users can access the system through a remote PC or smartphone connected to the Internet. The designed user interface to control and monitor the system is a web based application which is installed in the database server (controller). The 
said controller transmits the signals to the electrical switches interface. This interface together with the controller uses a coding protocol (all switched on/ all switched off/-state per port) for communication. Then, the load (electric outlet) captures the appropriate command whether switched off or switched on. The system's website displays the electricity consumption information and this information came from the monitoring interface which gets its data from the sub meter's signal. To ensure the reliability of service, the controller, interface, and load are all connected to the Uninterruptable Power Supply (UPS).

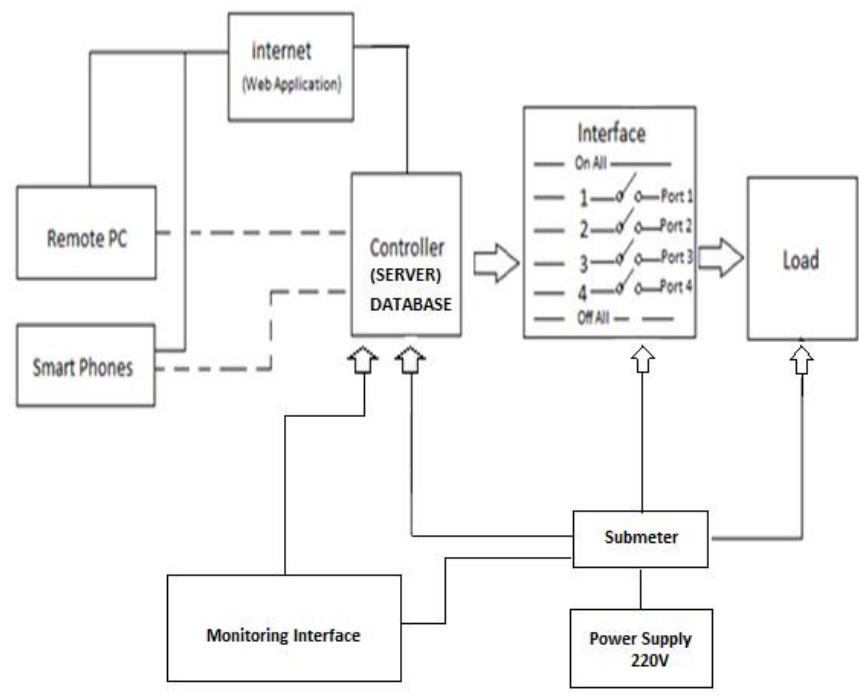

Fig. 1. System Architecture of Smart Home Electricity Management System using Cloud Computing (SHEMS)

\section{B. System Overview/ Pictorial Diagram}

Fig. 2 shows the pictorial diagram of SHEMS connected to four ports. Labelled \#1 is the electric sub meter where the overall consumption computation mainly came from.

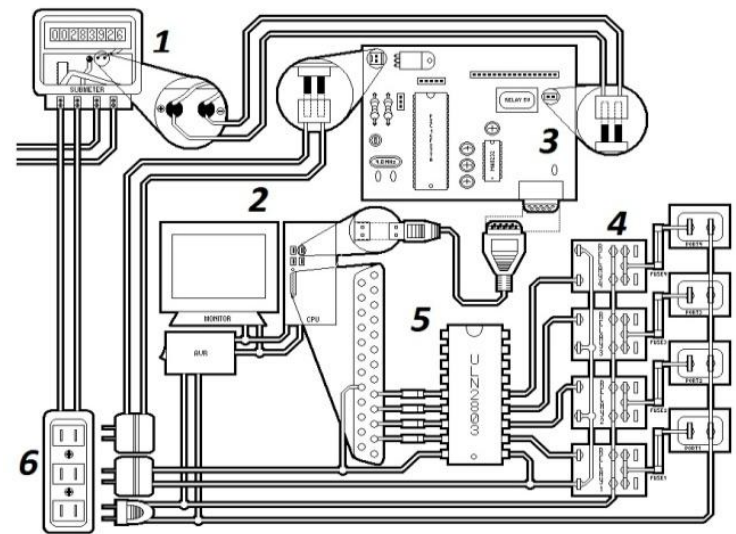

Fig. 2. Pictorial Diagram of Smart Home Electricity Management System using Cloud Computing (SHEMS)

The pulses coming from the electric sub meter is directed to the monitoring hardware interface labeled as \#3. This interface transmits the signals into the Controller (\#2) via RS 232 serial port. The Controller which serves as the Web server, is also connected to the Electrical switches labeled as \#5 and \#4 via Parallel port to utilize the electricity flow on the four (4) ports controlled by relays (\#4)

\section{Hardware}

Fig. 3 shows electronic switches included in the system to utilize the electric flow control (switch on and off). The maximum capacity of each electronic switch in the system is 10 Amperes. It can be upgraded into higher capacity electronic switches without affecting the software application controlling it.

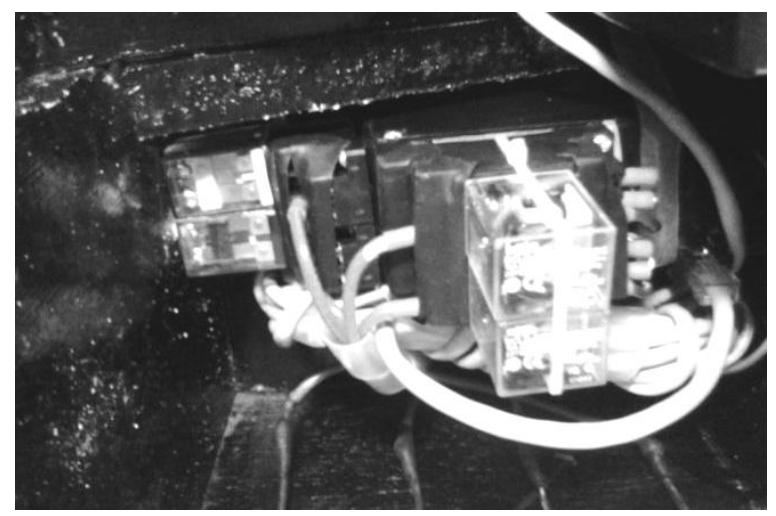

Fig. 3. Electronic Switches

Fig. 4 shows the monitoring hardware interface. The interface shown is connected to the Electronic sub meter and the Controller (Web server) to utilize the monitoring feature of the whole system. For hardware interface, the authors used Proteus as a development tool.

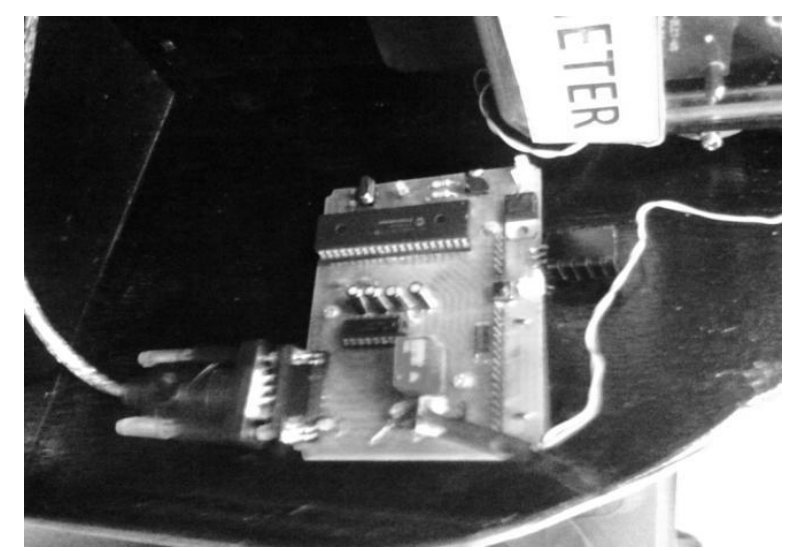

Fig. 4. Monitoring Hardware Interface

\section{Software}

The software is developed in C\# programming language and Microsoft Visual Studio (MVS). Moreover, to emphasize user friendliness, Macromedia Dreamweaver and PHP are used for the Graphical User Interface (GUI) of the system's website.

Fig. 5 shows the interface where the user can switch on and off the devices plugged in to the four (4) ports of the developed system.

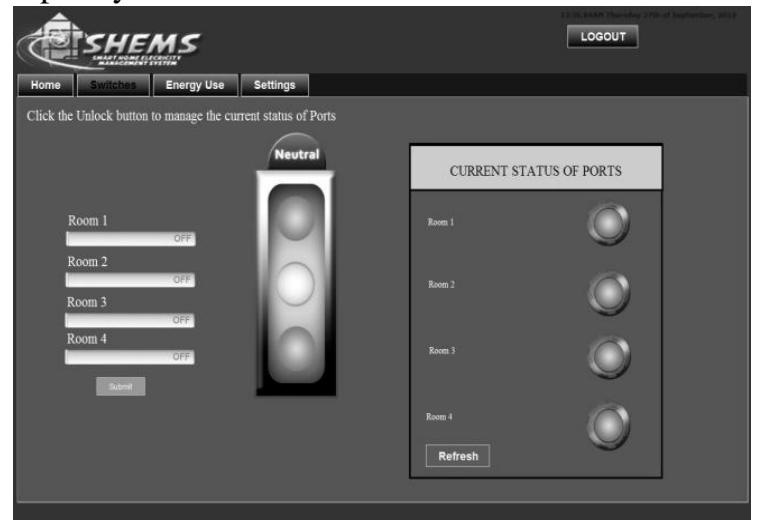

Fig. 5. Web interface for electronic switches 
Fig. 6 shows the interface of the consumption monitoring part of the system. It shows a bar graph that can show variations of electric consumption per day, per month, per year, and per port (power outlet).

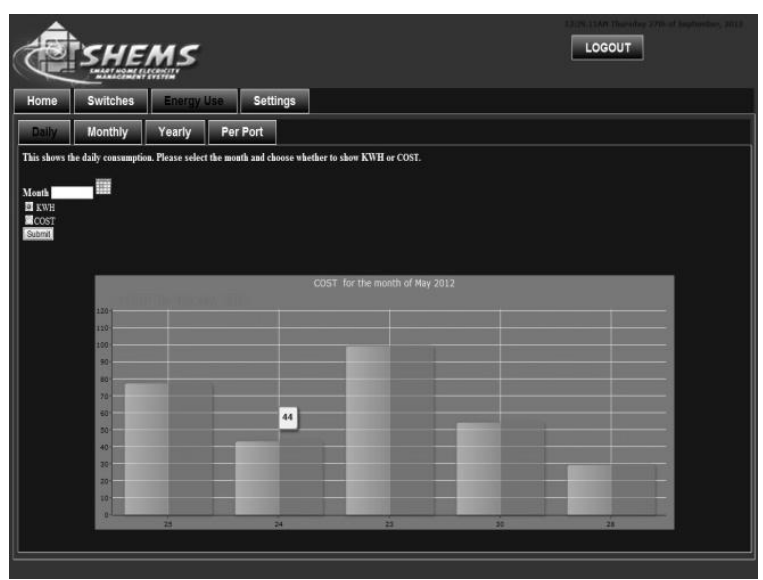

Fig. 6. Web interface for Monitoring electricity consumption

Fig. 7 shows the system's GUI wherein the user can update the price rate of the power service provider. This activity may facilitate the accuracy of the computed consumed electricity cost.

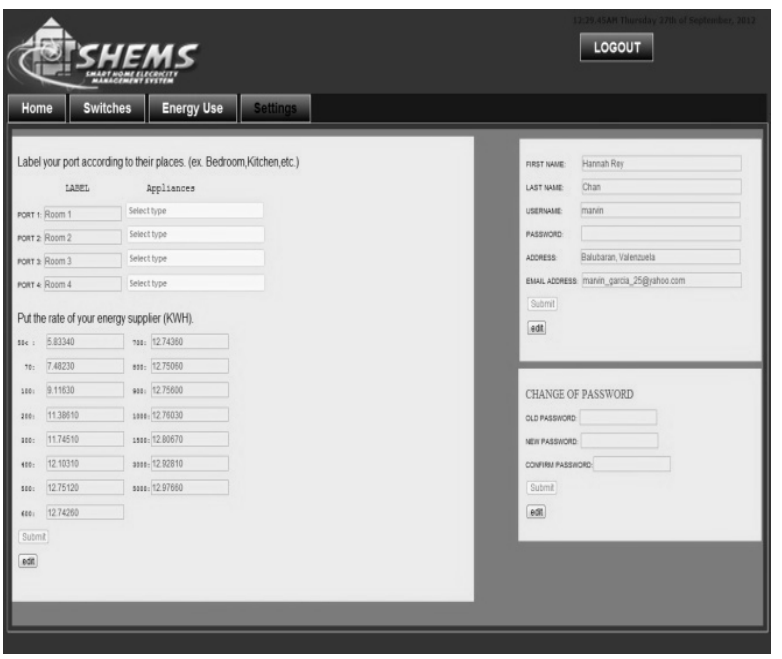

Fig. 7. Web interface for maintenance of the system.

\section{RESEARCH METHODS AND TECHNIQUES}

On the implementation and testing of SHEMS, certain materials and procedures are provided and conducted to achieve the desired output.

\begin{tabular}{|c|c|c|}
\multicolumn{3}{|c|}{ TABLE I: LIKERT SCALE } \\
\hline SCALE & RANGE & REMARKS \\
\hline 5 & $4.50-5.00$ & Excellent \\
\hline 4 & $3.50-4.49$ & Very Good \\
\hline 3 & $2.50-3.49$ & Good \\
\hline 2 & $1.50-2.49$ & Fair \\
\hline 1 & $1.00-1.49$ & Poor \\
\hline
\end{tabular}

With the use of survey questionnaires, a survey was conducted to fifteen (15) Faculty members of College of Computer Management and Information Technology (CCMIT), Polytechnic University of the Philippines, and to the four (4) Electricians from the Electrical Management Division of the said University. The survey questionnaire is grouped into four (4) sections such as system functionality, system usefulness, system effectiveness, and system acceptability. The respondents evaluated the developed System using the five-point rating scale which is based on the likert scale on Table I.

A system response test is also conducted to measure its response time using different Internet connection technology.

\section{RESUlTS AND DisCUSSIONS}

The following results depicted on Table II and Table III are based on the 5-point rating likert scale on Table I.

TABLE II: OVERALL PERFORMANCE OF THE SMART HOME ELECTRICITY

\begin{tabular}{|l|c|c|c|c|c|c|}
\hline \multirow{2}{*}{ Criteria } & \multicolumn{2}{|c}{ Faculty } & \multicolumn{2}{c|}{ Electricians } & \multicolumn{2}{c|}{ Composite } \\
\cline { 2 - 7 } & WM & VI & WM & VI & WM & VI \\
\hline Functionality & 4.34 & VG & 4.35 & VG & 4.34 & VG \\
\hline Usefulness & 4.44 & VG & 4.58 & E & 4.51 & E \\
\hline Effectiveness & 4.48 & VG & 4.75 & E & 4.61 & E \\
\hline Acceptability & 4.04 & VG & 4.50 & E & 4.27 & VG \\
\hline Overall Values & 4.32 & VG & 4.54 & E & 4.43 & VG \\
\hline
\end{tabular}

Legend:

WM= Weighted Mean

$\mathrm{VG}=$ Very Good

E- Excellent

VI- Verbal Interpretation

Table II shows the assessment by the Faculty members and the Electricians on the developed system. Given the highest point of 4.75 on effectiveness, the safeness of controlling the electrical devices is rated as excellent by the respondents. With the obtained overall weighted mean (WM) of 4.43 , the performance of the developed system was rated as Very Good (VG). This implies that the developed system provides a better and much safer way of managing electricity use.

As part of the study, the researchers also tried to find out if there are significant differences in the evaluation of the Faculty members and Electricians.

TABLE III: ASSESSMENT OF SMART HOME ELECTRICITY MANAGEMENT SYSTEM USING CLOUD COMPUTING

\begin{tabular}{|c|c|c|c|c|c|c|c|}
\hline \multirow{2}{*}{ Criteria } & \multicolumn{2}{|c|}{ Faculty } & \multicolumn{2}{c|}{ Electricians } & t- & VI & Decision \\
& WM & SD & WM & SD & value & & \\
\hline Functionality & 4.34 & 0.64 & 4.34 & 0.60 & 0.43 & NS & A \\
\hline Usefulness & 4.44 & 0.90 & 4.51 & 0.65 & 0.75 & NS & $\mathrm{A}$ \\
\hline Effectiveness & 4.48 & 0.64 & 4.61 & 0.39 & 1.21 & NS & $\mathrm{A}$ \\
\hline Acceptability & 4.04 & 0.71 & 4.27 & 0.63 & 1.26 & NS & $\mathrm{A}$ \\
\hline $\begin{array}{c}\text { Overall } \\
\text { values }\end{array}$ & 4.32 & 0.72 & 4.43 & 0.57 & 0.91 & NS & $\mathrm{A}$ \\
\hline
\end{tabular}

Legend:

WM- Weighted Mean

NS- Not Significant

A- Accepted

VI- Verbal Interpretation

Table III presents the result of assessment for finding the 
significant difference between the overall assessment of Electricians and Faculty members for the developed Smart Home Electricity Management System. With the overall T Value of 0.91 which is less than the critical value of 2.110 , it implies that there is no significant difference with regards to the assessment of Electricians and Faculty members of CCMIT.

Table IV illustrates the System response time using different types of Internet connection. The port commands are represented by 1 (on) and 0 (off). Each command is tested using three types of Internet connection such as Broadband stick, Wireless Canopy, and Direct Subscriber Line (DSL). With the fastest average response time of 1.2 seconds, the system connected to DSL is recommended to be used if the system will be fully implemented commercially.

TABLE IV: SySTEM RESPONSE ON PORT COMMANDS

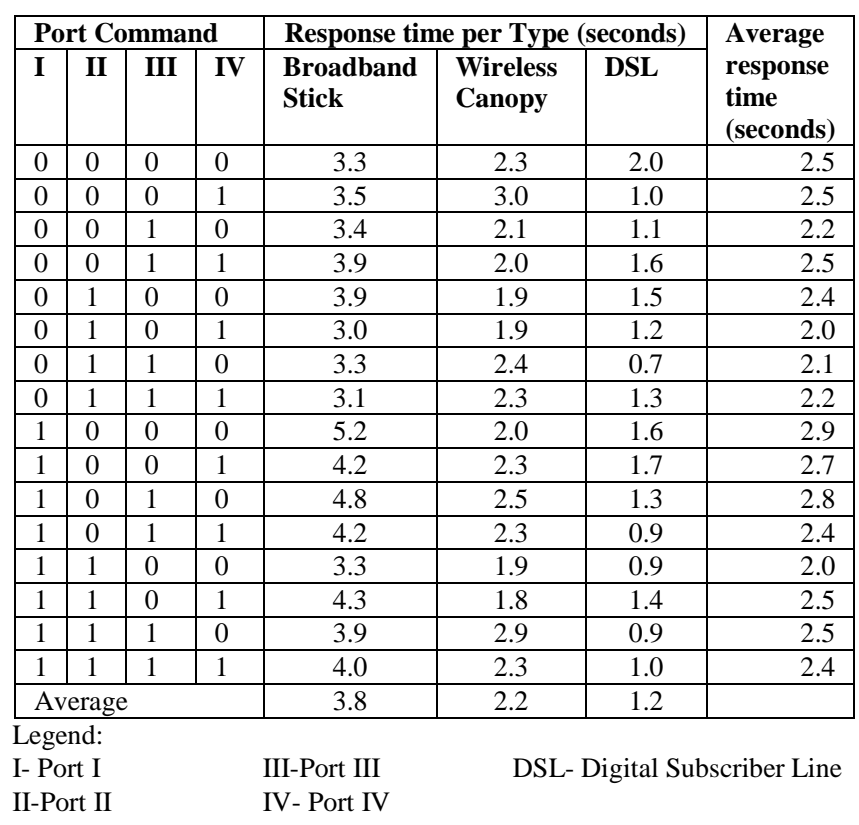

Table V presents System response time using different types of Internet connection per monitoring interfaces. The same three types of Internet connection technology are used for the simulation. At the end of the simulation, the system with DSL connection still got the fastest response time.

TABLE V: SYSTEM RESPONSE ON MONITORING INTERFACE

\begin{tabular}{|c|c|c|c|c|}
\hline \multirow{2}{*}{$\begin{array}{l}\text { Monitoring } \\
\text { Interface }\end{array}$} & \multicolumn{3}{|c|}{ Response time per Type $(\mathrm{mm} / \mathrm{ss})$} & \multirow{2}{*}{$\begin{array}{l}\text { Average } \\
\text { Response } \\
\text { Time }\end{array}$} \\
\hline & $\begin{array}{l}\text { Broadband } \\
\text { Stick }\end{array}$ & $\begin{array}{l}\text { Wireless } \\
\text { Canopy }\end{array}$ & DSL & \\
\hline Daily Consumption & $1: 34$ & $1: 03$ & $0: 25$ & $1: 00$ \\
\hline $\begin{array}{l}\text { Monthly } \\
\text { Consumption }\end{array}$ & $1: 30$ & $0: 58$ & $0: 21$ & $0: 56$ \\
\hline $\begin{array}{l}\text { Yearly } \\
\text { Consumption }\end{array}$ & $1: 36$ & $1: 05$ & $0: 25$ & $1: 02$ \\
\hline $\begin{array}{ll}\text { Consumption } & \text { Per } \\
\text { Port } & \end{array}$ & $1: 45$ & $1: 01$ & $0: 20$ & $1: 02$ \\
\hline Average & $1: 36$ & $1: 01$ & $0: 22$ & \\
\hline
\end{tabular}

\section{CONCLUSION AND FUTURE WORKS}

After the experiment and the analysis of the data based on the survey conducted, the proponents concluded that the
Smart Home Electricity Management System (SHEMS) complies the features needed in facilitating the control of electrical system remotely. The performance of the system as evaluated by the faculty members and the electricians is proven to be acceptable according to their preferences. Based on the data obtained by the proponents, there is no significant difference in the assessment rating given by the two (2) groups of respondents.

In the future, the authors will extend the work on using Arduino Programmable Module for the hardware interfaces to add more flexibility and efficiency. In addition, there should be audit trail to record the users account history. It is also recommended that the system should be implemented with faster computer processor and Internet connection to the main web server.

\section{REFERENCES}

[1] C. Bobcock. 4 Companies getting real results from cloud computing. [Online]. http://www.informationweek.com/hardware/data-centers/4companies-getting-real-results-from-cl/229000706, 2011

[2] M. Roxas, "Towards efficient e learning system based on moodle and SCORM cloud platform," Abstract of Thesis $8^{\text {th }}$ batch of JDS Fellows, 2012.

[3] N. Corsino. Global IT pioneer brings cloud computing to RP. [Online]. Available: http://www.gmanetwork.com/news/story/193749/scitech/global-itpioneer-brings-cloud-computing-to-rp, June 2010

[4] N. King. (September 2003). Smart home- definition. [Online]. Available: http://www.housingcare.org/downloads/kbase/2545.pdf,

[5] A. R. Al-Ali and M. Al-Rousan, "Java-based home automation system," IEEE Transactions on Consumer Electronics, vol. 50, issue 2. pp. 498-504, 2004

[6] N. S. Liang, L. C. Fu, and C. L. Wu, "An integrated, flexible and internet-based control architecture for home automation system in the internet era," in Proc. of 2002 IEEE International Conference On Robotic and Automation, 2002, pp. 1101-1106.

[7] H. Adao, R. Antunes, and F. Grilo, "Web-based control \& notification for home automation alarm systems," in Proc. International Conference on Automation and Robotics, World Academy of Science, Engineering and Technology, Cairo, Egypt, 2008, issue 13, pp. 152-156.

[8] M. S. H. Khiyal, A. Khan, and E. Shehzadi. (2009). SMS based wireless home appliance control system for automating appliances and security. [Online]. Available: http://iisit.org/Vol6/IISITv6p887894Khiyal592.pdf

[9] Virtual private network http://en.wikipedia.org/wiki/Virtual_private_network, November 2012

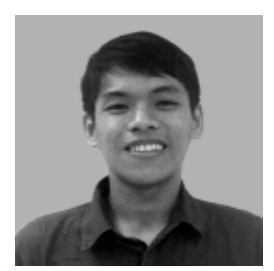

Marvin Rey G. Garcia is a Senior BS Computer Science student at Polytechnic University of the Philippines, Sta. Mesa, Manila, Philippines. He worked as a Technical Support for a year at 360 Marketing Inc based in Makati City, Manila, Philippines.

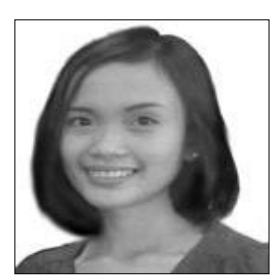

Hannah Roselle B. Chan is a Senior BS Computer Science student at Polytechnic University of the Philippines, Sta. Mesa, Manila, Philippines. She spent her time on the job training as a Web developer at 360 marketing Inc. based in Makati City, Philippines. 


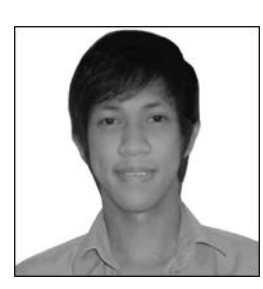

Christopher D. Celestial is a Senior BS Computer Science student at Polytechnic University of the Philippines He spent his time on the job training at Information Professionals Inc., (IPI) Quezon City, Philippines for two months.

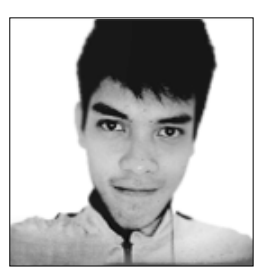

Arc Ezekiel P. Mercolesia is a Senior BS Computer Science student at Polytechnic University of the Philippines, Sta. Mesa, Manila, Philippines. He spent his time on the job training at Geodata Systems Technologies Inc., Philippines for two months.

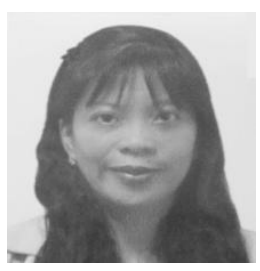

Benilda Eleonor V. Comendador obtained her Masters of Science in Global Information Telecommunication Studies, major in project research at Waseda University, Tokyo Japan in 2010. In addition, she obtained her Masters of Science in Information Technology at Ateneo Information Technology Institute, Makati City, Philippines in 2002. She is an Assistant Professor and former Chairperson in the Department of Information Technology of the College of Computer Management and Information Technology at the Polytechnic University of the Philippines. She presented several research paper on the following international conferences: (1) 2009 IEICE Society Conference, Niigata Japan; (2) e-Case \& e-Tech 2010 International Conference on e-Commerce, e-Administration, e-Society, e-Education, and e-Technology, Macau; (3International Journal of Arts \& Sciences (IJAS) Conference for Academic Disciplines in Las Vegas and (4)The Fifth International Conference on Mobile Computing and Ubiquitous Networking Seattle, U.S.A .

Prof. Comendador is currently member of Association of Computing Machineries(ACM), Philippine Computer Society(PCS), and Philippine Association for Business Educators (PAFBE), Inc.

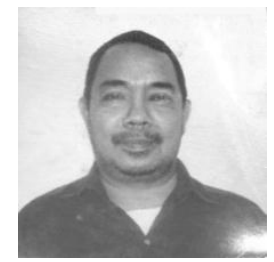

Grant Bernardo Cornell obtained his Doctorate in Education Major in Industrial Education Management at Eulogio Amang Rodriguez Institute of Science and Technology (EARIST), Philippines. He also finished Masters of Technician Education Major in Electronics Technology at Marikina Institute of Science and Technology, Marikina City, Philippines. He is the current Director of Research Services in EARIST, Sampaloc, Manila, Philippines and a part-time faculty member of the Polytechnic University of the Philippines. He presented several research papers on the following conferences: (1)2012 Strengthening Research Skills and Capabilities of NSTP and Community Extension Educators and Workers and other Educators Across Discipline, Jose Rizal Memorial State University, Philippines;(2) 2012 Research Capability Building and Output Dissemination through Collaborative Endeavour, Capiz State University, Philippines. He is also a Collaborator in the Design and Development of Solar Powered Lighting System in EARIST. 